\title{
Fabrikasi dan Karakterisasi Antena Mikrostrip Loop Co-Planar Waveguide dua Lapis Substrat untuk Komunikasi $C$-Band dan $\mathrm{Ku}$-Band
}

\author{
Erni Maryati Rahayu, ${ }^{*}$ Yono Hadi Pramono, dan Ali Yunus Rohedi \\ Jurusan Fisika-FMIPA, Institut Teknologi Sepuluh Nopember \\ Kampus ITS Sukolilo, Surabaya 61111
}

\begin{abstract}
Intisari
Antena Mikrostrip Loop Co-Planar Waveguide dua lapis substrat untuk aplikasi komunikasi $C$-Band dan Ku-Band telah difabrikasi dan karakterisasi. Parameter-parameter fisis yang dikarakterisasi meliputi VSWR (Voltage Standing Wave Ratio), return loss, dan impedansi. Substrat yang digunakan untuk fabrikasi antena pada penelitian ini adalah FR4 dengan permitivitas relatif 4,47. Penentuan dimensi antena dilakukan menggunakan fasilitas Tool Box perancangan Antena yang tersedia di Laboratorium Opto-Elektronika Jurusan Fisika FMIPAITS. Ukuran antena yang difabrikasi adalah $42 \mathrm{~mm} \times 49 \mathrm{~mm} \times 3 \mathrm{~mm}$, dengan feed line $5 \mathrm{~mm} \times 13 \mathrm{~mm}$, CPW $3 \mathrm{~mm} \times 13 \mathrm{~mm}$, loop $11 \mathrm{~mm} \times 19 \mathrm{~mm}$, patch $7 \mathrm{~mm} \times 12 \mathrm{~mm}$, dan slot $20 \mathrm{~mm} \times$ lebar $7 \mathrm{~mm}$. Hasil karakterisasi Network Analyzer tipe HP 8753ES pada frekuensi kerja 3,698 GHz adalah return loss $-34,021$ $\mathrm{dB}$, VSWR 1,041, dan impedansi 52,031 $\Omega$, sedangkan untuk pada frekuensi kerja 5,585 $\mathrm{GHz}$ adalah return loss $-24,893 \mathrm{~dB}$, VSWR 1,121 , dan impedansi 56,037 $\Omega$. Nilai VSWR yang mendekati 1 pada kedua frekuensi kerja tersebut menunjukkan bahwa daya masukan ditransmisikan hampir keseluruhan ke udara dengan porsi kecil yang direfleksikan balik ke dalam osilator/generator pulsa. Sedangkan return loss yang dihasilkan antena $<-15 \mathrm{~dB}$ berada pada rentang nilai yang dapat diterima untuk aplikasi komunikasi $C$-Band dan $K u$-Band, hal ini didukung dengan nilai impedansinya yang mendekati impedansi karakteristik ideal $50 \Omega$.
\end{abstract}

KATA KUNCI: antena mikrostrip, CPW, frekuensi kerja $C$-Band dan $K u$-Band.

\section{PENDAHULUAN}

Antena mikrostrip merupakan antena yang terbuat dari lapisan logam yang dipisahkan oleh bahan dielektrik. Keunggulan antena mikrostrip terutama kompatibel dengan desain MMIC (Monolithic Microwave Integrated Circuits). Kekompakan dan ketahanannya terhadap lingkungan yang ekstrim (ruggedness) meluaskan pemanfaatannya pada aerospace dan komunikasi satelit. Antena mikrostrip terdiri dari lapisan strip logam tipis sebagai elemen peradiasi yang ditempelkan pada salah satu sisi suatu substrat dielektrik yang memiliki permitivitas relatif $2,2 \leq \epsilon_{r} \leq 12$, sedangkan sisi lawannya berupa lembaran logam konduktor tipis yang lebar sebagai ground plane [1].

\section{TEORI}

Antena merupakan komponen penting dalam sistem komunikasi yang berfungsi untuk meradiasikan atau menerima gelombang elektromagnetik. Selain sebagai alat untuk mengirim atau menerima energi radiasi elektromagnetik, antena juga digunakan untuk mengoptimalkan energi radiasi pada arah tertentu dan menekannya pada arah yang lain. Sistem

*E-MAIL: ernimr@physics.its.ac.id
TABEL I: Pengelompokan pita frekuensi

\begin{tabular}{lc}
\hline \hline Band & $\begin{array}{c}\text { I.E.E.E Microwave Band } \\
\text { Frequency Range, GHz }\end{array}$ \\
\hline $\mathrm{HF}$ & $0.003-0.030$ \\
$\mathrm{VHF}$ & $0.030-0.300$ \\
$\mathrm{UHF}$ & $0.300-1.00$ \\
$\mathrm{~L}$ & $1.00-2.00$ \\
$\mathrm{~S}$ & $2.00-4.00$ \\
$\mathrm{C}$ & $4.00-8.00$ \\
$\mathrm{X}$ & $8.00-12.00$ \\
$\mathrm{~K}_{u}$ & $12.00-18.00$ \\
$\mathrm{~K}$ & $18.00-27.00$ \\
$\mathrm{~K}_{a}$ & $27.00-40.0$ \\
& \\
Millimeter & $40.0-300.00$ \\
Submillimeter & greater than 300.00 \\
\hline \hline
\end{tabular}

komunikasi yang memanfaatkan gelombang elektromagnetik (microwave) adalah komunikasi nirkabel (wireless). Setiap struktur desain dari antena mikrostrip memiliki kemampuan yang berbeda dalam merespon gelombang elektromagnetik yang selanjutnya berakibat pada frekuensi yang diterima. Dari segi kualitas dan efisiensi gelombang mikro merupakan pilihan utama untuk dijadikan media propagasi. Pengelompokan pita frekuensi yang menurut I.E.E.E. Microwave Band terlihat pada Tabel 1 [2].

Parameter Refleksi 


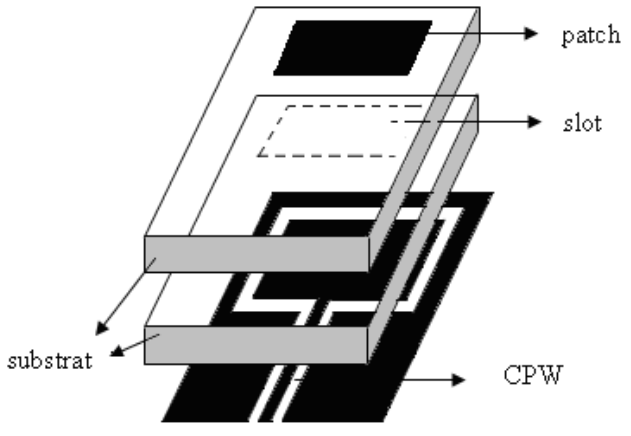

Gambar 1: Pemodelan antena mikrostrip loop CPW dua lapis substrat untuk komunikasi $\mathrm{C}$-Band dan $\mathrm{Ku}$-Band

\section{- Standing Wave}

Peristiwa standing wave (gelombang berdiri) terjadi jika terdapat dua gelombang yang merambat pada arah berlawanan dalam media yang sama. Standing wave dipresentasikan dalam besaran Voltage Standing Wave Ratio, nilai VSWR antara 1 sampai tak hingga, jika nilai VSWR adalah 1, maka tidak ada pantulan di dalam mikrostrip.

$$
V S W R=\frac{V_{\max }}{V_{\min }}
$$

\section{- Return Loss $(R L)$}

RL diperoleh dari hasil pengukuran pada Network Analyzer. Nilai return loss yang dinyatakan dalam satuan $\mathrm{dB}$ berkisar antara - $\propto$ sampai $0(\mathrm{~dB})$.

$$
R L=20 \log _{10}(\rho)
$$

- Bandwidth Frekuensi Kerja

Penghitungan lebar pita (bandwidth) frekuensi kerja bermanfaat untuk mengetahui rentang daerah frekuensi yang dapat digunakan ketika antena mikrostrip masih dapat bekerja secara efektif. Antena dapat bekerja efektif jika nilai return loss $<-15 \mathrm{~dB}$.

\section{FABRIKASI DAN KARAKTERISASI}

Geometri antena mikrostrip loop CPW dua lapis substrat untuk komunikasi $\mathrm{C}$-Band dan $\mathrm{Ku}$-Band yang difabrikasi, ditunjukkan Gambar 1 dan 2. Penentuan dimensi antena dilakukan menggunakan fasilitas Tool Box perancangan Antena yang tersedia di Laboratorium Opto-Elektronika Jurusan Fisika FMIPA-ITS. Dimensi antena yang difabrikasi adalah $42 \mathrm{~mm} \times 49 \mathrm{~mm} \times 3 \mathrm{~mm}$, dengan ukuran feed line $5 \mathrm{~mm} \times$ $13 \mathrm{~mm}$, ukuran CPW $3 \mathrm{~mm} \times 13 \mathrm{~mm}$, ukuran loop $11 \mathrm{~mm} \times$ $19 \mathrm{~mm}$, ukuran patch $7 \mathrm{~mm} \times 12 \mathrm{~mm}$, dan ukuran slot $20 \mathrm{~mm}$ $\times$ lebar $7 \mathrm{~mm}$. Karakterisasi antena menggunakan Network Analyzer tipe HP 8753ES meliputi rentang frekuensi kerja, return loss, dan VSWR. Pengukuran ini dilakukan di Laboratorium Gelombang Mikro, Antena dan Propagasi, PENSITS. Hasil ketiga besaran tersebut ditunjukkan dalam Gambar 4 dan 5. (a)

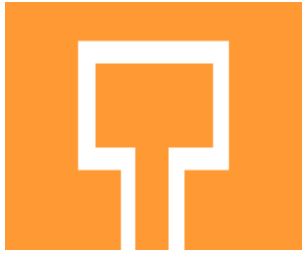

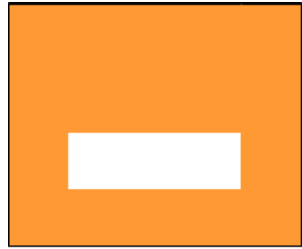

(b)

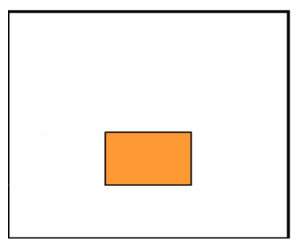

(c)

Gambar 2: Dimensi (a) CPW, (b) slot, (c) patch pada antena mikrostrip loop CPW dua lapis substrat untuk komunikasi $\mathrm{C}$ dan $\mathrm{Ku}$ Band

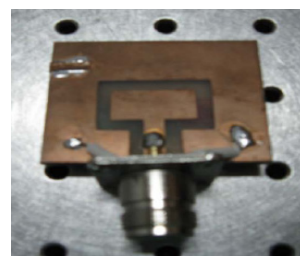

(a)

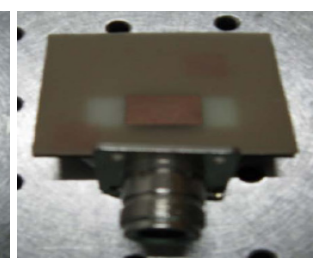

(b)
Gambar 3: Antena mikrostrip loop CPW dua lapis substrat untuk komunikasi $\mathrm{C}$ dan $\mathrm{Ku}$-Band yang telah difabrikasi pada penelitian ini

Pada Gambar 4 terlihat nilai return loss terkecil sebesar $-34,021 \mathrm{~dB}$ pada frekuensi $3,698 \mathrm{GHz} ;-24,893 \mathrm{~dB}$ pada frekuensi 5,585 $\mathrm{GHz}$, dan $-22,521 \mathrm{~dB}$ pada frekuensi 5,388 $\mathrm{GHz}$. koefisien refleksi terkecil sebesar 0,020 pada frekuensi $3,698 \mathrm{GHz}, 0,057$ pada frekuensi 5,585 GHz, dan 0,075 pada frekuensi 5,388 GHz.

Pada grafik dalam Gambar 5, pada frekuensi 3,698 GHz didapatkan $\mathrm{RL}=-34,021 \mathrm{~dB}$, VSWR 1,041 dan impedansi $52,031 \Omega$, sedangkan pada frekuensi $5,585 \mathrm{GHz}$ didapatkan $\mathrm{RL}=-24,893 \mathrm{~dB}$, VSWR 1,121, dan impedansi 56,037 $\Omega$.

Berdasarkan hasil pengukuran pada Tabel 2, pada frekuensi

TABEL II: Hasil pengukuran fabrikasi antena yang telah memenuhi standar

\begin{tabular}{cccccc}
\hline \hline $\begin{array}{c}\text { No. Frekuensi } \\
(\mathrm{MHz})\end{array}$ & $\begin{array}{r}\text { return loss } \\
(\mathrm{dB})\end{array}$ & $\begin{array}{c}\text { Koefisien refleksi } \\
(\mathrm{dB})\end{array}$ & & $\begin{array}{c}\text { VSWR Impedansi } \\
\Omega\end{array}$ \\
\hline & & & & & \\
1 & 3665.724 & -21.987 & 0.080 & 1.173 & 58.643 \\
2 & 3698.712 & -34.021 & 0.020 & 1.041 & 52.031 \\
3 & 3731.996 & -21.178 & 0.087 & 1.191 & 59.567 \\
4 & 5340.370 & -21.048 & 0.089 & 1.195 & 59.725 \\
5 & 5388.428 & -22.521 & 0.075 & 1.162 & 58.086 \\
6 & 5535.212 & -21.145 & 0.088 & 1.192 & 59.607 \\
7 & 5585.024 & -24.893 & 0.057 & 1.121 & 56.037 \\
\hline \hline
\end{tabular}




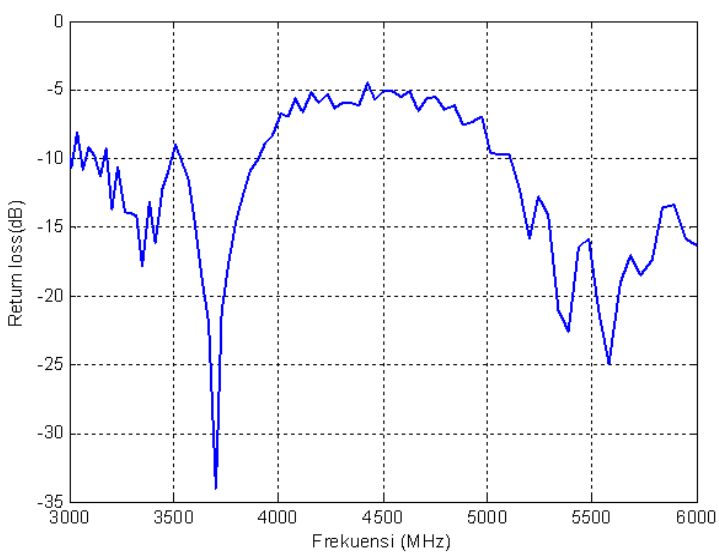

(a)

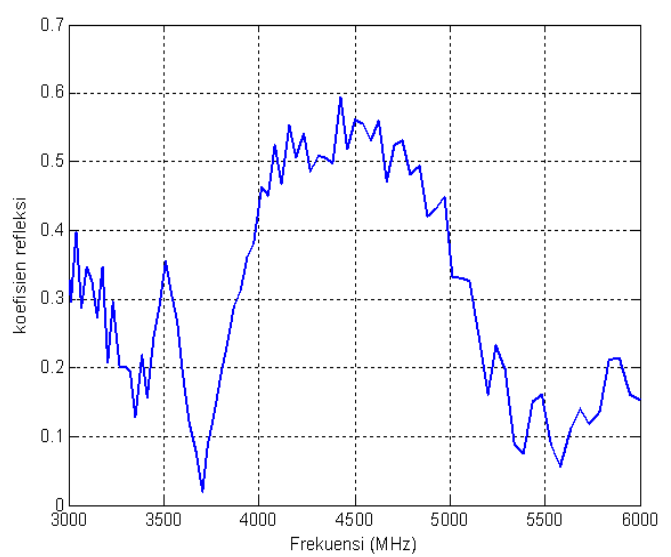

(b)

Gambar 4: Hubungan frekuensi dengan (a) return loss, (b) koefisien refleksi

3,665 GHz, 3,698 GHz, $3731 \mathrm{GHz}$, ternyata return loss $<-15$ $\mathrm{dB}$, koefisien refleksi $\approx 0,1<\mathrm{VSWR}<2$, dan impedansi berada pada nilai 40-60 $\Omega$ dengan demikian antena yang telah difabrikasi dalam penelitian ini dapat bekerja pada frekuensi $S$-band yang berada pada range $2,0-4,0 \mathrm{GHz}$. Adapun pada frekuensi 5,340 GHz, 5,388 GHz, 5,535 GHz, 5,585 GHz, return loss $<-15 \mathrm{~dB}$, koefisien refleksi $\approx 0<\rho<1$, dan impedansi berada pada nilai 40-60 $\Omega$ sehingga antena yang telah difabrikasi dalam penelitian ini dapat bekerja pada frekuensi $C$-Band yang berada pada range 4,0-8,0 GHz.

Dari grafik pada Gambar 6 terlihat dari koordinat (5293,14,11) hingga $(5789,-17,32)$ antena mikrostrip loop CPW yang telah difabrikasi pada penelitian ini masih dapat bekerja, yaitu pada bandwidth $496 \mathrm{MHz}$. Sedangkan pada frekuensi S-band didapatkan bandwidth yang berada diantara koordinat $(3633,-18,51)$ hingga $(3766,-17,41)$ yaitu $133 \mathrm{MHz}$.

Alat karakterisasi yang digunakan yaitu Network Analyzer tipe HP 8753ES di Laboratorium Gelombang Mikro, Antena dan Propagasi PENS-ITS hanya dapat digunakan sam- pai frekuensi $6 \mathrm{GHz}$, sehingga pengukuran return loss, koefisien frekuensi, dan VSWR pada frekuensi $\mathrm{Ku}$-Band tidak

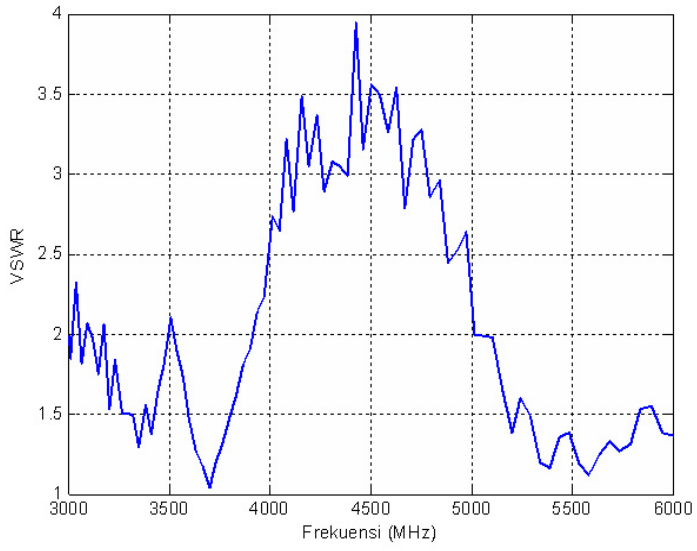

(a)

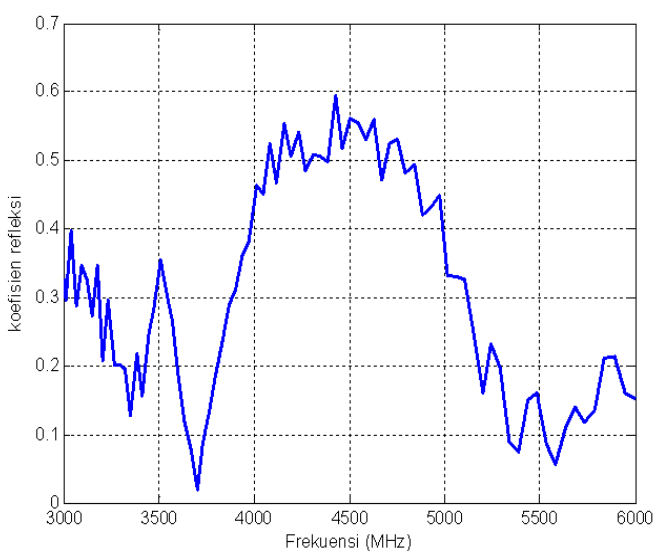

(b)

Gambar 5: Hubungan frekuensi dengan (a) VSWR, (b) impedansi

dapat dilakukan. Tetapi antena pada penelitian ini telah diujicobakan dipasang sebagai pengganti antena di dalam LNB pada parabola.

\section{SIMPULAN}

Hasil pengukuran pada frekuensi $3,698 \mathrm{GHz}$ menunjukkan return loss terkecil $\mathrm{RL}=-34,021 \mathrm{~dB}$, VSWR 1,041, dan impedansi 52,031 $\Omega$; pada frekuensi $5,388 \mathrm{GHz}$ menunjukkan $\mathrm{RL}=-22,521 \mathrm{~dB}$, VSWR 1,162, dan impedansi 58,086 $\Omega$; pada frekuensi $5,535 \mathrm{GHz}$ didapatkan $\mathrm{RL}=-21,145$ dB, VSWR 1,192, dan impedansi 59,607 $\Omega$; pada frekuensi $5,340 \mathrm{GHz}$ didapatkan RL = -21,048 dB, VSWR 1,195, dan impedansi 52,031 $\Omega$. Hal ini telah memenuhi kriteria standar penggunaan antena. 


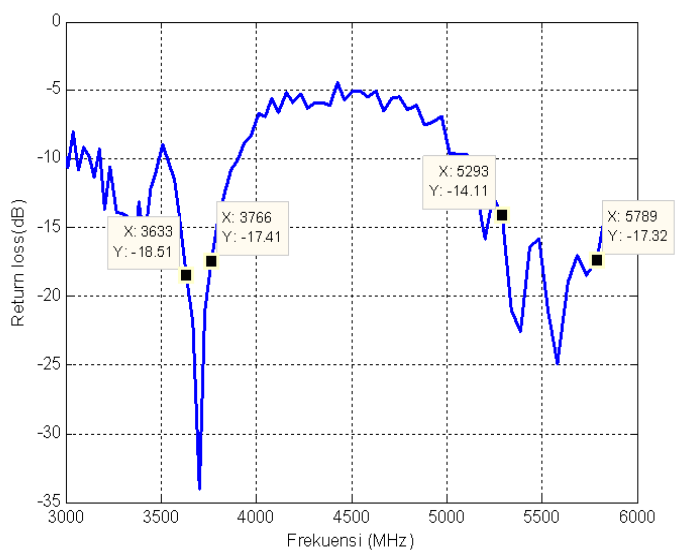

Gambar 6: Bandwidth antena hasil fabrikasi

[1] Balanis, C. A, Antenna Theory Analysis and Design (Second edition, John Wiley \& Sons, New York, 1997).

[2] Edwards, T, Foundations For Microstrip Circuit Design (Second edition, John Wiley and Son, Inc Canada, 1992).

[3] Hund, E., Microwave communications. Component and Circuit (McGraw-Hill, New York, 1989).

[4] Kamimura, Y., Haneishi, M., Radiation Properties of Microstrip Antenna Fed by Coplanar Waveguide, Dept. of Electrical and Electric Engineering Saitama University Urawa, Saitama 338, Japan, Proceeding of ISAP '96, Chiba, Japan, 1996.

[5] Kraus, John, Electromagnetics With Applications (Fifth edition, McGraw-Hill, New York, 1999).

[6] Matsuzawal, Shin-ichiro, Tsuji, Takeshi, Ito, Koichi, Radiation of Circularly Polarized Printed Antena Composed of Slot Fed By Coplanar Waveguide, Faculty of Engineering, Chiba University, Proceeding of ISAP '96, Chiba, Japan, 1996.
[7] Saydam, Gouzali, Teknologi Telekomunikasi: Perkembangan dan Aplikasi (Alfabeta, Bandung, 2005).

[8] Sugiono, Pramono, Yono H., Pembuatan Filter Mikrostrip Band Pass 2,4 GHz Dengan Struktur Satu Lapis, Proceeding of The 7th Seminar on Intelligent Technology and Its Applications (SITIA), Surabaya-Indonesia. Hal.II-K-44 - II-K-48, 2006.

[9] Suhana, Shoji, Shigeki, Teknik Telekomunikasi (PT Pradnya Paramita, Jakarta, 2002).

[10] Sujarwati, N., Pramono, Yono H. dan Rubiyanto, A., Analisis Karakteristik Antena CPW SLOT dan PATCH Dengan FDTD, Prosiding SFA 2002, Jurusan Fisika FMIPA ITS, 2002.

[11] Young, L., Haider, S., Neve, M., Dr., Microstrip Patch Antennas for Broadband Indoor Wireless System, Part 4 Project Report, Departemen of Electrical \& Elektronics Engineering, The University of Aucland Faculty of Engineering, 2003. 